AperTO - Archivio Istituzionale Open Access dell'Università di Torino

\title{
Lipid-Based Nanoparticles in Cardiovascular Molecular Imaging
}

\section{This is the author's manuscript}

Original Citation:

Availability:

This version is available http://hdl.handle.net/2318/131208

since 2017-05-26T09:51:44Z

Published version:

DOI:10.1007/s12410-012-9180-2

Terms of use:

Open Access

Anyone can freely access the full text of works made available as "Open Access". Works made available under a Creative Commons license can be used according to the terms and conditions of said license. Use of all other works requires consent of the right holder (author or publisher) if not exempted from copyright protection by the applicable law. 


\section{(3) \\ UNIVERSITÀ DEGLI STUDI DI TORINO}

This is an author version of the contribution published on:

Current Cardiovascular Imaging Reports

Volume 6, Issue 1, 2013, Pages 69-75.

ISSN: 19419066Source Type: Journal Original language: English

DOI: 10.1007/s12410-012-9180-2Document Type: Review 


\section{Lipid-based Nanoparticles in Cardiovascular Molecular Imaging}

Simonetta Geninatti Crich, Diego Alberti, Laura Orio, Rachele Stefania, Dario Longo, Silvio Aime*

Department of Molecular Biotechnology and Health Sciences; University of Torino, via Nizza 52, Torino, Italy.

- Simonetta Geninatti Crich.

Department of Molecular Biotechnology and Health Sciences

University of Torino

via Nizza 52, 10126 Torino (Italy)

e-mail: simonetta.geninatti@unito.it

- Diego Alberti

Department of Molecular Biotechnology and Health Sciences

University of Torino

via Nizza 52, 10126 Torino (Italy)

e-mail: albertidiego@hotmail.com

- Laura Orio

Department of Molecular Biotechnology and Health Sciences

University of Torino

via Nizza 52, 10126 Torino (Italy)

e-mail: laura_orio@libero.it

- Rachele Stefania

Department of Molecular Biotechnology and Health Sciences

University of Torino

via Nizza 52, 10126 Torino (Italy)

e-mail: rachele.stefania@unito.it

- Silvio Aime (corresponding author)

University of Torino

Department of Molecular Biotechnology and Health Sciences

via Nizza 52, 10126 Torino (Italy)

e-mail: silvio.aime@unito.it

Keywords: atherosclerosis, MRI, Gd(III) complexes, nanoparticles 


\begin{abstract}
.
The Gd(III) complexes currently used as MRI contrast agents are hydrophilic agents that distribute in the vascular and extracellular compartments. The visualization of atherosclerotic plaques requires systems endowed with lipophilic characteristics. Several Gd(III) complexes bearing lipophilic substituents have been reported. Among them $\mathrm{Gd}(\mathrm{III})$ complexes containing one or two aliphatic chains appears particularly useful for the intended application. These amphiphilic $\mathrm{Gd}$ (III) complexes have been incorporated into various type of supramolecular adducts that ensure enough sensibility for their detection in MR images of atherosclerotic plaques. Much attention has been devoted to the use of HDL and LDL Gd-loaded particles. The presence of long aliphatic chain(s) promotes the spontaneous aggregation of these complexes to form micelles that may associate as such to the surface of HDL particles. It has been shown that the transfer of single amphiphilic complexes into the lipidic core of the particles is possible by de-assembling the micelles through the formation of "host-guest" adducts with $\beta$-cyclodextrin. Gd-loaded liposomes have also been successfully tested in plaque detection as well as perfluoronanoparticles loaded with CEST agents.
\end{abstract}




\section{Introduction.}

The hallmarks of vulnerable atherosclerotic plaques are the presence of a high number of infiammatory cells and of a heterogeneous composition with high variability even within the same individual. [1] In the last decade an intense research activity, aimed at exploiting non-invasive clinically available imaging, has increased in order to detect and characterize the atherothrombotic disease in its various stages and at different anatomical sites. Magnetic Resonance Imaging (MRI) is a promising technique to study cardiovascular diseases "in vivo". In fact, although its sensitivity is lower in comparison to nuclear and optical modalities, the high spatial resolution ( $<100 u m)$ of ${ }^{1} \mathrm{H}$ MRI provides detailed morphological and functional informations, and the absence of radiation makes it safer than techniques based on the use of radioisotopes.[2] MRI contrast is the result of a complex interplay that combines instrumental parameters and longitudinal $\left(T_{1}\right)$ and transverse $\left(T_{2}\right)$ water proton relaxation times. In both clinical and experimental settings it is customary to alter the endogenous contrast by the use of contrast agents (CAs) that decrease the longitudinal and transverse relaxation time of water protons in the tissues were they distribute.[3] Most of CAs used in clinical settings are polyaminocarboxylate complexes of $\mathrm{Gd}^{3+}$ ion that contains seven unpaired electrons. The ligands are multidentate (seven or eight donor atoms) in order to form complexes with very high thermodynamic and kinetic stability thus limiting the "in vivo" release of the toxic free metal ion. In a ${ }^{1} \mathrm{H}$ MR image, there is a direct proportionality between the observed relaxation enhancement and the concentration of the paramagnetic MRI reporter. However, MRI suffers from an intrinsic insensitivity with respect to the competing imaging modalities. This drawback has to be overcome by designing suitable amplification procedures unusually based on the accumulation of the imaging agents at the targeting sites.[4] A general strategy for achieving this goal utilizes nanosized systems such as liposome, micelles, microemulsions, polymers etc...that are able to deliver a huge payload of $\mathrm{Gd}$ complexes[5-6]. The nanocarriers may be functionalized with suitable vectors that provide the overall particles with the required recognition capabilities towards the selected target. A straightforward extension of this approach has involved the exploitation of naturally occurring nanosized aggregates such as the different types of lipoproteins (HDL, LDL) [7] that enter the atherosclerotic plaque without the need of further functionalization with specific vectors.

Currently, there are no clinically established methods to non-invasively differentiate between stable and vulnerable plaques and to identify rupture prone plaques. Therefore, there are many activities devoted to the development of Molecular Imaging protocols able to visualize, in real time, the expression of specific receptors, enzymes, inflammation cell activity (macrophages, neutrophils, and lymphocytes), and neovascularisation in order to find useful markers of plaque instability. In this review, the use of both natural and synthetic lipid based nanoparticles as vectors for a high 
payload of contrast agents units to the atherosclerotic plaques is surveyed and their diagnostic prediction ability is discussed.

\section{High Density Lipoproteins. (HDL)}

HDLs are endogenous nanoparticles with a diameter of 7-13 $\mathrm{nm}$ that accumulate at atherosclerotics plaques. They are composed of cholesterol, phospholipids (phosphatidylcholines are particularly abundant) [8] and apolipoproteins. The major apolipoprotein of HDL is apoA-I, (although other apolipoproteins may also be present) which is responsible for scaffolding the size and shape of natural HDL particles. Several characteristics of HDLs make these systems highly attractive for molecular delivery: namely i) the amphiphilic nature of HDLs allows their loading with hydrophobic and amphiphilic small molecules, drugs, and proteins; ii) HDLs, being endogenous structures, are biocompatible; iii) cell surface receptors for HDL are very active and offer the potential for targeted drug delivery to cells that express them.[9] Three routes to prepare Gd-based MRI HDL particles have been explored, and they are based on: i) native HDL; ii) reconstituted HDL; ii) synthetic HDL, respectively. All of them rely on the use of amphiphilic Gd-complexes and several structural types have been proposed. Due to the toxicity issues associated with free Gd ions, it is crucial that chelators bind $\mathrm{Gd}^{3+}$ ions with high thermodynamic stability. This requirement is particularly stringent in molecular imaging protocols where Gd containing probes own prolonged circulation life times[10]. In fact, it has been shown that $\mathrm{Gd}$ complexes with thermodynamic association constants $\leq 10^{17}$ when added to cell incubation media, show net transfer of Gd ions to the cell membrane followed by a slower internalization process.[11]. Figure 1 shows two types of amphiphilic Gd-complexes used to prepare Gd-loaded HDL particles. They contain one or two C14 or C16 aliphatic chains that allow their incorporation. into HDL particles. Diethylenetriaminepentaacetic distearylamide (DTPA-SA) and 1,2-dimyristoyl-sn-glycero-3phosphoethanolamine diethylenetriamine pentacetic acid (DTPA-DMPE) with eight coordinating atoms leaving one site available to coordinate a water molecule whereas AAZTA ligand has only seven coordinating atoms thus allowing the coordination of two water molecules.[12] As a consequence, Gd-AAZTA-C17-labeled HDL particles have a four times higher longitudinal relaxivity (the key parameter of $\mathrm{MRI}$ contrast-generating potential), making these systems very efficient contrast agents[13]. Once dissolved in water, these amphiphilic Gd-complexes form stable micelles with different critical micellar concentrations (CMC). In fact, Gd-DTPA derivatives, that are functionalized with two aliphatic chains, show a cmc $<0.05 \mathrm{mM}$ whereas Gd-AAZTA-C17 has a $\mathrm{CMC}=0.1 \mathrm{mM}$.[14] Briley-szabo and coworkers [13] showed that the successful incorporation of the Gd-complexes into native HDL is strongly dependent upon the CMC of the used amphiphile. At concentrations below the CMC the amphiphilic $\mathrm{Gd}(\mathrm{III})$-complexes are easily integrated into the lipoproteins and stable HDL adducts with high stability constants are formed. At Gd-complexes 
concentrations above the $\mathrm{CMC}$, larger particles are formed. These particles display a relaxivity higher than that of the particles obtained with some amphiphilic Gd complexes below the cmc. The larger size implies that the particles tumble more slowly, yielding an increased relaxivity. The reason for the formation of larger sized HDL particles is not well elucidated, but it may be due to the formation of fused HDL species as suggested by Pownall (15). In these studies exposure of HDL to cholate above the CMC values results in the loss of ApoA-I and phospholipid from the lipoprotein surface. This structural change causes the exposure of the neutral lipid core to the surrounding aqueous phase thereby inducing the fusion of two or more ApoA-I/phospholipiddepleted HDL particles, as depicted in Figure 2. In order to avoid the formation of these large adducts it is possible to deassemble the Gd-complex containing micelles in aqueous solution by adding an excess of $\beta$-cyclodextrin ( $\beta$-CD). In fact, $\beta$-CD yields a molecular dispersion of the amphiphilic complexes, as a consequence of the formation of supramolecular "host-guest" adducts because the lipophilic chains have a very good affinity for the hydrophobic cavity of $\beta$-CD (Figure 3). Upon the addition of HDL, an equilibrium between the monomeric Gd-complex/ $\beta$-CD adducts and Gd-complex/HDL particle is established. Since the stability of $\mathrm{Gd}$-complex/HDL particle is higher, the equilibrium is shifted toward the formation of the latter adducts. By using this method an efficient HDL contrast agent containing up to $80 \mathrm{Gd}$-complex units has been prepared. An alternative approach relies on the use of HDL reconstituted with phospholipids and contrast agents, with or without cholesterol. The procedure consists of delipidation (by standard methods) of HDL particles to yield apo-HDL proteins, mainly apo-A-I. Using this method, Frias and coworkers [16] incorporated the phospholipid-based contrast agent, Gd-DTPA-DMPE into the reconstituted particle. The size of the resulting particles was approximately $9 \mathrm{~nm}$ diameter and each particle contained between 15 and 20 molecules of Gd-DTPA-DMPE. They targeted atherosclerotic plaques and observed an enhancement of the MRI signal that wss related to the plaque macrophage content. This basic platform structure was then modified in order to improve the uptake by macrophages in the atherotic tissue by incorporating the Apo-E derived peptide (P2A2) into the phospholipid layer. This peptide was derived from the LDL-receptor-binding domain of ApoE, and it has been shown to facilitate cellular uptake of nanoparticles [17]. The uptake of these P2A2 containing HDL was measured in J774A.1 macrophages in vitro, using fluorescence measurements and $\mathrm{MRI}$ and compared with the traditionally reconstituted HDL. The new formulation produced greater contrast than the original HDL formulation also in the MRI images of aortas of ApoE-/- mice, indicating that the P2A2 peptide maintains the same enhanced effect in vivo. A new artificial HDL-based platform, labeled with MRI and Optical agents, has been recently developed using synthetic peptides (37pA) instead of natural ApoA-I[18]. This approach could have the advantage of avoiding the use of plasma derived products and must be more suitable for a clinical translation. These synthetic HDL-based contrast agents were synthesized via hydration of a 
mixed phospholipids film with a solution of $37 \mathrm{pA}$ followed by sonication, filtration and concentration. Some of these phospholipids were gadolinium labeled or fluorophore labeled. 37pAHDL was tested as an atherosclerosis-specific contrast agent in ApoE-/- mice on a 9.4 T smallanimal scanner. At $24 \mathrm{~h}$ post injection the signal intensity in the aorta of the ApoE-/- mice increased by an average of $94 \%$, as compared to pre-injection images.(Figure 4) When 37pA-HDL was tested in non-atherosclerotic, wild-type mice the increase in signal intensity in aortas region was not significant. This finding clearly demonstrates the specificity of $37 \mathrm{pA}-\mathrm{HDL}$ for the visualization of atherosclerotic tissue.

\section{Low Density Lipoproteins (LDL).}

The low-density lipoproteins (LDLS) are another member of plasma lipoproteins family and represent the main biological carriers of unesterified and esterified cholesterol to extrahepatic tissues. The membrane associated protein ApoB100 mediates the recognition of LDLs receptors and the subsequent uptake into cells through receptor-mediated endocytosis [19]. Altered LDLR levels are found in a variety of pathological conditions (e.g., atherosclerosis) [20] and several tumors overexpress LDLRs to supply the high cholesterol demand of rapidly dividing cells [21]. In the literature there are many examples on the use of LDL as carriers for imaging agents to tumor cells (Table 1). As a consequence of their size (18-25 nm), LDL can incorporate a high number of MRI contrast agents (up to 400 probes per protein). The long reorientational time of the Gdcomplex incorporated in the supramolecular adduct yields higher relaxivities with respect the free complex in particular at relatively low magnetic field strengths (e.g.1 T). LDLs appear ideal for the delivery of drug and imaging agents since they are able to circulate in the bloodstream for a significant amount of time. Furthermore, LDLs are more efficient in terms of loading capacity (with respect the smaller HDL).

Table 1. Types of imaging agents / LDL nanoformulations used in cancer diagnostic.

\begin{tabular}{|l|l|l|l|l|l|}
\hline $\begin{array}{l}\text { Imaging } \\
\text { Technique }\end{array}$ & Imaging agent & Tumor type & $\begin{array}{l}\text { Agent/LDL } \\
\text { Latio } \\
\text { procedure } \\
\text { (loading } \\
\text { efficiency) }\end{array}$ & Reference \\
\hline MRI & Gd-DTPA-SA & $\begin{array}{l}\text { Hepg2 (human } \\
\text { hepatocarcinoma) }\end{array}$ & $\begin{array}{l}\text { core } \\
\text { loading }\end{array}$ & $200: 1$ & {$[22]$} \\
\hline $\begin{array}{l}\text { Confocal } \\
\text { Microscopy }\end{array}$ & $\begin{array}{l}\text { meso to- } \\
\text { meso ethyne-bridged } \\
\text { tris[(porphinato)zinc(II)] }\end{array}$ & $\begin{array}{l}\text { B16 (murine } \\
\text { melanoma) }\end{array}$ & $\begin{array}{l}\text { core } \\
\text { loading }\end{array}$ & $30: 1$ & {$[23]$} \\
\hline $\begin{array}{l}\text { Cryo-imager } \\
\text { (optical }\end{array}$ & $\begin{array}{l}\text { l,1_-dioctadecyl- } \\
3,3,3,3 \_-\end{array}$ & Hepg2 (human & surface & $34: 1$ & {$[24]$} \\
\hline
\end{tabular}




\begin{tabular}{|c|c|c|c|c|c|}
\hline imaging) & $\begin{array}{l}\text { tetramethylindotricarbocyanine } \\
\text { iodide }\end{array}$ & hepatocarcinoma) & loading & & \\
\hline $\begin{array}{l}\text { Two-Channel } \\
\text { I\&Q } \\
\text { Spectrometer }\end{array}$ & $\begin{array}{l}\text { tetra-t-butyl silicon } \\
\text { naphthalocyanine } \\
\text { bisoleate }\end{array}$ & Hepg2 & $\begin{array}{l}\text { core } \\
\text { loading }\end{array}$ & $100: 1$ & [25] \\
\hline CT & $\begin{array}{l}\text { 2-oleoylglycerol } \\
\text { bis(iodopanoate }\end{array}$ & Hepg2 & $\begin{array}{l}\text { core } \\
\text { loading }\end{array}$ & nd & [26] \\
\hline $\begin{array}{l}\text { Confocal } \\
\text { Fluorescent } \\
\text { Imaging }\end{array}$ & hypericin & $\begin{array}{l}\text { U87-MG } \\
\text { Glioma) }\end{array}$ & $\begin{array}{l}\text { core } \\
\text { loading }\end{array}$ & 100:1 & [27] \\
\hline $\begin{array}{l}\text { Confocal } \\
\text { Microscopy }\end{array}$ & dioleyl fluorescein, & Human fibroblast & $\begin{array}{l}\text { core } \\
\text { loading }\end{array}$ & nd & [28] \\
\hline MRI & Gd-AAZTA-C17 & B16, Hepg2 & $\begin{array}{l}\text { surface } \\
\text { loading }\end{array}$ & $300: 1$ & [29] \\
\hline MRI & $\begin{array}{l}\text { [N-(DOTAMA- } \\
\text { C6)carbamoylmethyl]C'- } \\
\text { palmitamidomethyl-ortho- } \\
\text { carborane }\end{array}$ & $\begin{array}{l}\text { B16, Hepg2, U87- } \\
\text { MG }\end{array}$ & $\begin{array}{l}\text { surface } \\
\text { loading }\end{array}$ & 190:1 & [30] \\
\hline
\end{tabular}

In spite of these positive characteristics, Gd-loaded LDLs have been less used for the visualization of atherosclerotic lesions. In fact, it is well accepted that high serum levels of LDL play a main role in the initiation and progression of the pathology through LDL matrix interaction in the subendothelial space of an initiating plaque. Recently Yamakoshi and coworkers [31] reported on the preparation of LDL-based nanoparticles for MRI detection of atheroplaques in mice apoE-/-or LDL-/- models. LDL particles were loaded with GdDO3A-OA (Figure 5) which bears an oleic acid anchor to facilitate incorporation into the lipid layer of the particle. In vivo studies using atherosclerotic mouse models showed a significant $\mathrm{Gd}^{3+}$ retention in the atheroplaques by ICP/MS and good enhancement in MRI images. These results clearly demonstrate that LDL nanoparticles are a useful vehicle for delivering a high payload of imaging agents to atherosclerosis exploiting the natural affinity for plaque components of LDL-based particles.

\section{Liposomes.}

Liposomes are colloidal particles that are composed of either natural or synthetic amphiphilic lipids and have been proposed as carriers for both therapeutic and contrast agents to the atherosclerotic plaques as the payload can be encapsulated in their internal aqueous cavity and/or intercalated in the phospholipid bilayer, thus allowing the transport of both hydrophilic and hydrophobic compounds (figure 6). A specific class of liposomes, named "long time circulating" polyethylene glycol (PEG)-coated liposomes, is able to accumulate in solid tumors as a consequence of 
increased microvascular permeability and defective lymphatic drainage [32]. Since, atherosclerotic lesions are often associated with increased membrane permeability, (PEG)-coated liposomes have been proposed to detect atherosclerosis/neointimal thickening [33], in ApoE-KO mouse model of atherosclerosis. Gd-DTPA-BSA has been used as MRI contrast agent intercalated in the phospholipid bilayer of these (PEG)-coated liposomes. No abnormalities were detectable with either non-enhanced imaging methods ( $T 1-\mathrm{w}$, T2-w, and PD-w) or conventional Gd-DTPA contrast enhancement at the time points at which a strong signal enhancement was observed with paramagnetic liposomes. Thus, the use of the liposomal contrast agent considerably improved the detection of the pathology that was otherwise poorly visible by traditional MRI scanning. In order to target liposomes to specific markers of atherosclerosis it is possible to add to the phospholipid formulation a small \% of a functionalized phospholipid. The targeting moiety is conjugated at the end of the PEG chain, and it may consists of peptides (or peptide analogues) containing the ArgGly-Asp (RGD), phosphatidylserine (PS), folic acid, etc. In fact, it is well known that the RGD peptide sequence has high affinity for $\alpha_{\nu} \beta_{3}$-integrin that is a key endothelial cell receptor overexpressed by neo-formed vessels.[34] Its specificity and ubiquitous expression has made it a specific marker for the visualisation of vascular changes using nuclear or other imaging modalities. Alternatively, imaging strategies that pursue the visualization of inflammatory cells appear particularly attractive in view of the fundamental role of inflammation in atherosclerosis [35]. Macrophage targeting strategies are particularly attractive due to their ubiquitous presence and positive correlation with complications of atherosclerosis. It is known that exposed phosphatidylserine (PS) residues present in the outer surface of apoptotic cells promotes macrophage recognition by macrophage scavenger receptor/CD36 followed by rapid phagocytosis [36]. Accordingly, it has been hypothesized by Maiseyeu and co-workers [37] that mimicking apoptosis with liposomes containing PS may represent an attractive approach for molecular imaging of atherosclerosis. Liposomal composition can be easily modulated to include different lipids into the vesicle double layer as well as to entrap paramagnetic materials and fluorescence tags for in vivo monitoring of tissue/cell-specific delivery. In this approach, a simple route to prepare nonPEGylated liposomes containing the lipophilic Gd chelate-Gd-DTPA-SA and fluorescent organic dye Rhodamine B has been used to assess cellular uptake. PS liposomes appear to be avidly taken up by macrophages through a specific pathway for PS-containing epitopes, as these are analogous to exteriorized PS residues as a consequence of apoptosis. No significant decreases in $\mathrm{T}_{1}$ shortening was detected beyond $2 \% \mathrm{PS}$, while a continuing increase in fluorescent uptake of Gd-PS has been observed in "in vitro" studies at least to the $12 \%$ PS concentration. This is likely due to the intracellular localization of paramagnetic liposomes inside vesicles (endosomes and/or lisosomes) due to the internalization process based on receptor mediated endocytosis. In fact, the liposome intracellular distribution in vesicles can limit the 
attainable relaxation enhancement as a consequence of the reduced water exchange across the barriers among the different compartments.[38-40]. On the contrary, changes in fluorescence measurements are typically linear over the ranges studied.

\section{Targeted Paracest Nanoparticles.}

Among MRI contrast agents, CEST (chemical exchange saturation transfer) agents have the unique property of yielding a so-called "frequency-encoded" contrast that may allow, analogous to optical imaging probes, the visualization of different agents in the same region.[41,42] The frequency-encoded MRI contrast generated by CEST agents is the result of the selective irradiation at the resonance frequency of the labile protons of the probe, whose exchange with the bulk water protons causes a decrease of their MRI signal. In such a way, a rather small concentration of mobile protons (e.g. in the millimolar range) may be detected in the MR image. The sensitivity of a CESTagent is primarily dependent on the number of NMR-equivalent mobile protons that operate the saturation transfer (ST) to the bulk water resonance. One method of increasing the sensitivity of PARACEST agents is to incorporate multiple metal chelates into a macromolecular scaffold such us perfluoronanoparticles.(PFC) Cai and coworkers [43] explored the use of PARACEST loaded with PFC nanoparticles by coupling 19F-MRI quantification and a mathematical modeling of the PARACEST signal. The particles were targeted to fibrin that is an abundant component of thrombi and an early marker of ruptured atherosclerotic plaques. Identification of fibrin could help detect ruptured plaques and direct therapeutic interventions to prevent or improve the consequences of a heart attack or stroke.

\section{Concluding Remarks.}

The herein surveyed results show that amphiphilic Gd complexes can be loaded on lipoproteins yielding highly sensitive MRI reporters. The targeting properties of HDL and LDL appear not to be significantly affected by the Gd-payload thus making these systems efficient agents for plaque visualization. The clinical translation of these interesting results will rely, first al all, on the design of biodegradable Gd-containing amphiphilic complexes. In fact, amphiphilic molecules like the Gdcomplexes functionalized with the long aliphatic chains reported in this survey, are expected to have good affinity for membrane phospholipid components as well as for several transporting proteins. Ultimately, they are expected to accumulate in liver and spleen. In principle their transformation into biodegradable molecules can be tackled by introducing an hydrolizable linkage between the lipophilic moiety and the $\mathrm{Gd}$ (III) complex. Obviously, the design of the agents has to avoid that the release of the Gd containing complex occurs only after the targeting step. Finally, one may foresee a larger involvement of the emerging class of CEST agents in atherosclerosis MRI diagnosis. These agents allows multiple epitope detection in the same MR image, a task that 
appears highly relevant to the characterization of vulnerable plaques as their instability is the result of several concomitant factors whose simultaneous assessment is clearly most in need.

\section{Acknowledgements .}

This research was performed in the framework of the EU COST Action TD1004, "Theranostics Imaging and Therapy: an Action to Develop Novel Nanosized Systems for Imaging-Guided Drug Delivery" and supported by Regione Piemonte (PIIMDMT, ATHIMAG,and nano-IGT projects), MIUR (PRIN 2009235JB7), ENCITE project (FP7-HEALTH-2007-A) and Consorzio Interuniversitario di Ricerca in Chimica dei Metalli dei Sistemi Biologici (CIRCMSB).

\section{References.}

Papers of particular interest, published recently, have been

highlighted as follows:

- Of importance

•• Of major importance

[1] den Adel B, Bovens SM, Boekhorst BT, Strijkers GJ, Poelmann RE, van der Weerd L, Pasterkamp G. Histological validation of iron-oxide and gadolinium based MRI contrast agents in experimental atherosclerosis: The do's and don't's. atherosclerosis.2012.07.028, http://dx.doi.org/10.1016/j.

[2] A. Rinck, Magnetic Resonance in Medicine, Blackwell Scientific Publications, Oxford, 2003.

[3] Caravan P. Strategies for increasing the sensitivity of gadolinium based MRI contrast agents. Chemical Society Reviews. 2006; 35: 512-523.

[4] Terreno E, Dastrù W, Delli Castelli D, Gianolio E, Geninatti Crich S, Longo D, Aime S. Advances in metal-based probes for MR molecular imaging applications. Curr Med Chem. 2010;17(31):3684-700.

[5] Mulder WJ, Strijkers GJ, van Tilborg GA, Griffioen AW, Nicolay K. Lipid-based nanoparticles for contrast-enhanced MRI and molecular imaging. NMR Biomed. 2006;19:142-64.

[6] Bumb A, Brechbiel MW, Choyke P. Macromolecular and dendrimer-based magnetic resonance contrast agents. Acta Radiol. 2010;51:751-67.

[7] * * Cormode DP, Frias JC, Ma Y, Chen W, Skajaa T, Briley-Saebo K, Barazza A, Williams KJ, Mulder WJ, Fayad ZA, Fisher EA. HDL as a contrast agent for medical imaging. Clin Lipidol. 2009; 4(4):493-500. This article describes the use of HDL as carriers for MRI contrast agent for atherosclerosis.

[8] Frias JC, Ma Y,Williams KJ, Fayad ZA, Fisher EA Properties of a Versatile Nanoparticle Platform Contrast Agent To Image and Characterize Atherosclerotic Plaques by Magnetic Resonance Imaging Nano Lett., 2006; 6:2220-2224. 
[9] Skajaa T, Cormode DP, Falk E, Mulder WJ, Fisher EA, Fayad ZA. High-density lipoproteinbased contrast agents for multimodal imaging of atherosclerosis. Arterioscler Thromb Vasc Biol. 2010;30:169-76.

[10] Chao CC, Yang CC, Hsiao CH, Pan MK, Lin CH, Hsieh ST. Nephrogenic systemic fibrosis associated with gadolinium use. J Formos Med Assoc. 2008;107:270-4.

[11] Cabella C, Geninatti Crich S, Corpillo D, Barge A, Ghirelli C, Bruno E, Lorusso V, Uggeri F, Aime S. Cellular labeling with Gd(III) chelates: only high thermodynamic stabilities prevent the cells acting as 'sponges' of $\mathrm{Gd}^{3+}$ ions. Contrast Media Mol Imaging. 2006;1(1):23-9.

[12] Aime S, Calabi L, Cavallotti C, Gianolio E, Giovenzana GB, Losi P, Maiocchi A, Palmisano G, Sisti M. [Gd-AAZTA]-: a new structural entry for an improved generation of MRI contrast agents. Inorg Chem. 2004;43:7588-90.

[13] Briley-Saebo KC, Geninatti-Crich S, Cormode DP, Barazza A, Mulder WJ, Chen W, Giovenzana GB, Fisher EA, Aime S, Fayad ZA. High-relaxivity gadolinium-modified high-density lipoproteins as magnetic resonance imaging contrast agents. J Phys Chem B. 2009;113(18):62839.

[14] Gianolio E, Giovenzana GB, Longo D, Longo I, Menegotto I, Aime S. Relaxometric and modelling studies of the binding of a lipophilic Gd-AAZTA complex to fatted and defatted human serum albumin. Chemistry. 2007;13(20):5785-97.

[15] Pownall HJ. Remodeling of human plasma lipoproteins by detergent perturbation.

Biochemistry. 2005;44:9714-22.

[16] Frias JC, Williams KJ, Fisher EA, Fayad ZA. Recombinant HDL-like nanoparticles: a specific contrast agent for MRI of atherosclerotic plaques. J Am Chem Soc. 2004;126:16316-7.

[17] Chen W, Vucic E, Leupold E, Mulder WJ, Cormode DP, Briley-Saebo KC, Barazza A, Fisher EA, Dathe M, Fayad ZA. Incorporation of an apoE-derived lipopeptide in high-density lipoprotein $\mathrm{MRI}$ contrast agents for enhanced imaging of macrophages in atherosclerosis. Contrast Media Mol Imaging. 2008;3:233-42.

[18] Cormode DP, Chandrasekar R, Delshad A, Briley-Saebo KC, Calcagno C, Barazza A, Mulder WJ, Fisher EA, Fayad ZA. Comparison of synthetic high density lipoprotein (HDL) contrast agents for MR imaging of atherosclerosis. Bioconjug Chem. 2009; 20(5):937-43.

[19] Brown MS and Goldstein JL. Receptor-mediated endocytosis: insights from the lipoprotein receptor system. Proc Natl Acad Sci USA, 1979; 76: 3330 - 3337.

[20] Choudhury RP, Fuster V, and Fayad ZA Molecular, cellular and functional imaging of atherothrombosis. Nat Rev Drug Discov, 2004, 3, 913-925.

[21] Firestone RA. Low density lipoprotein as a vehicle for targeting antitumor compounds to cancer cells. Bioconjug Chem, 1994; 5:105 - 113.

[22] Corbin IR, Li H, Chen J., Lund-Katz Sy, Zhou R, Glickson JD, Zheng G. Neoplasia, LowDensity Lipoprotein Nanoparticles as Magnetic Resonance Imaging Contrast Agents, 2006; 8: 488 -498 . 
[23] Wu SP, Lee I, Ghoroghchian PP, Frail PR, Zheng G, Glickson JD, Therien MJ.Near-infrared optical imaging of B16 melanoma cells via low-density lipoprotein-mediated uptake and delivery of high emission dipole strength tris[(porphinato)zinc(II)] fluorophores. Bioconjug Chem. 2005; 16(3):542-50.

[24] Li H, Zhang Z, Blessington D, Nelson DS, Zhou R, Lund-Katz S, Chance B, Glickson JD, Zheng G. Carbocyanine labeled LDL for optical imaging of tumors. Acad Radiol. 2004;11(6):66977.

[25] Song L, Li H, Sunar U, Chen J, Corbin I, Yodh AG, Zheng G. Naphthalocyanine-reconstituted LDL nanoparticles for in vivo cancer imaging and treatment. Int J Nanomedicine. 2007;2(4):76774.

[26] Hill ML, Corbin IR, Levitin RB, Cao W, Mainprize JG, Yaffe MJ, Zheng G. Acad Radiol. In vitro assessment of poly-iodinated triglyceride reconstituted low-density lipoprotein: initial steps toward CT molecular imaging. 2010;17:1359-65.

[27] Huntosova V, Buzova D, Petrovajova D, Kasak P, Nadova Z, Jancura D, Sureau F, Miskovsky P. Development of a new LDL-based transport system for hydrophobic/amphiphilic drug delivery to cancer cells. Int J Pharm. 2012; 15:463-71.

[28] Krieger M, Smith LC, Anderson RG, Goldstein JL, Kao YJ, Pownall HJ, Gotto AM Jr, Brown MS. Reconstituted low density lipoprotein: a vehicle for the delivery of hydrophobic fluorescent probes to cells. J Supramol Struct. 1979;10:467-78.

[29] Geninatti Crich SG, Lanzardo S, Alberti D, Belfiore S, Ciampa A, Giovenzana GB, Lovazzano C, Pagliarin R, Aime S. Magnetic resonance imaging detection of tumor cells by targeting lowdensity lipoprotein receptors with Gd-loaded low-density lipoprotein particles. Neoplasia. 2007; 9:1046-56.

[30] Geninatti-Crich S, Alberti D, Szabo I, Deagostino A, Toppino A, Barge A, Ballarini F, Bortolussi S, Bruschi P, Protti N, Stella S, Altieri S, Venturello P, Aime S. MRI-guided neutron capture therapy by use of a dual gadolinium/boron agent targeted at tumour cells through upregulated low-density lipoprotein transporters. Chemistry. 2011, 18;17:8479-86.

[31] Yamakoshi Y, Qiao H, Lowell AN, Woods M, Paulose B, Nakao Y, Zhang H, Liu T, Lund-Katz $S$, Zhou R. LDL-based nanoparticles for contrast enhanced MRI of atheroplaques in mouse models. Chem Commun (Camb). 2011;47:8835-7.

[32] Gabizon A, Shmeeda H, Barenholz Y. Pharmacokinetics of pegylated liposomal Doxorubicin: review of animal and human studies. Clin Pharmacokinet. 2003;42:419-36.

[33] Mulder WJ, Douma K, Koning GA, van Zandvoort MA, Lutgens E, Daemen MJ, Nicolay K, Strijkers GJ. Liposome-enhanced MRI of neointimal lesions in the ApoE-KO mouse. Magn Reson Med. 2006 May;55(5):1170-4.

[34] Gaertner FC, Kessler H, Wester HJ, Schwaiger M, Beer AJ, Radiolabelled RGD peptides for imaging and therapy. Eur J Nucl Med Mol Imaging. 2012;39:S126-38.

[35] Kelly C, Jefferies C, Cryan SA. Targeted liposomal drug delivery to monocytes and macrophages. J Drug Deliv. 2011;2011:727241. 
[36] Henson P. M., Bratton D. L., Fadok V. A. Apoptotic cell removal. Curr. Biol. 2011;11: R795R805.

[37] * Maiseyeu A, Mihai G, Kampfrath T, Simonetti OP, Sen CK, Roy S, Rajagopalan S, Parthasarathy S. Gadolinium-containing phosphatidylserine liposomes for molecular imaging of atherosclerosis. J Lipid Res. 2009;50:2157-63. This article describes the use of phosphatidylserineenriched liposomes as carriers for MRI contrast agent to detect atherosclerotic plaque and colocalize with macrophages in experimental atherosclerosis.

[38] Terreno E, Geninatti Crich S, Belfiore S, Biancone L, Cabella C, Esposito G, Manazza $A D$, Aime S. Effect of the intracellular localization of a $\mathrm{Gd}$-based imaging probe on the relaxation enhancement of water protons. Magn Reson Med. 2006; 55:491-7.

[39] Gianolio E, Arena F, Strijkers GJ, Nicolay K, Högset A, Aime S. Photochemical activation of endosomal escape of MRI-Gd-agents in tumor cells. Magn Reson Med. $2011 ; ; 65: 212-9$.

[40] Kok MB, Hak S, Mulder WJ, van der Schaft DW, Strijkers GJ, Nicolay K. Cellular compartmentalization of internalized paramagnetic liposomes strongly influences both $\mathrm{T} 1$ and T2 relaxivity. Magn Reson Med. 2009;61:1022-32.

[41] Soesbe TC, Wu Y, Dean Sherry A. Advantages of paramagnetic chemical exchange saturation transfer (CEST) complexes having slow to intermediate water exchange properties as responsive MRI agents. NMR Biomed. 2012. doi: 10.1002/nbm.2874.

[42] Terreno E, Dastrù W, Delli Castelli D, Gianolio E, Geninatti Crich S, Longo D, Aime S. Advances in metal-based probes for MR molecular imaging applications. Curr Med Chem. 2010;17:3684-700.

[43] Cai K, Kiefer GE, Caruthers SD, Wickline SA, Lanza GM, Winter PM. Quantification of water exchange kinetics for targeted PARACEST perfluorocarbon nanoparticles. NMR Biomed. 2012;25:279-85.

\section{Figure legends.}

Figure 1. Schematic representation of Gd-DTPA-DMPE and Gd-AAZTA-C17.

Figure 2. Schematic depiction of the fusion of two or more ApoA-I/phospholipid-depleted HDL particles as a consequence of the interaction with amphiphilic Gd(III)-complexes micelles.

Figure 3. Formation of the supramolecular "host-guest" adducts formed by amphiphilic $\mathrm{Gd}(\mathrm{III})$-complexes and $\beta$-cyclodextrin.

Figure 4. Representative MR images of the aorta of apoE-KO mice pre- and 24 hours post-injection with 18A-Gd (left panels) and 37pA-Gd (right panels). Figure adapted with permission from Cormode DP et al. Bioconjug Chem. 2009; 20(5):937-43. Copyright 2009 American Chemical Society.

Figure 5. Schematic representation of the Gd(III)DO3A-OA complex. 
Figure 6. Schematic depiction of a stealth liposome loaded with both amphiphilic and hydrophilic Gd(III) -complexes. 


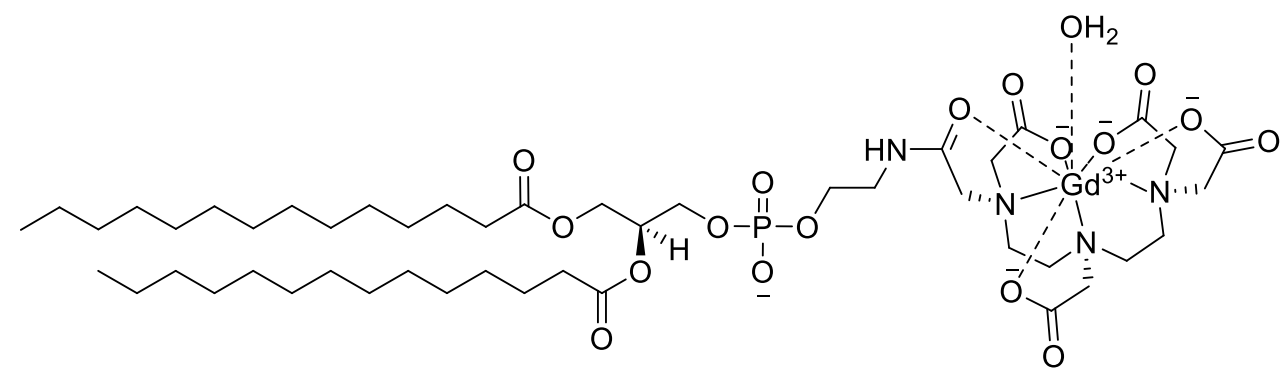

Gd-DTPA-DMPE

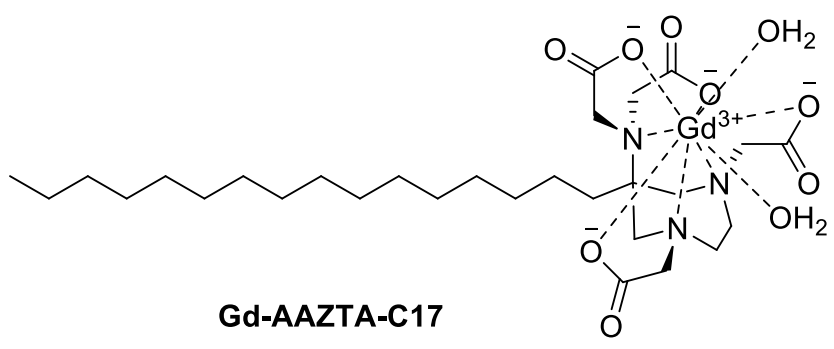

Figure 1

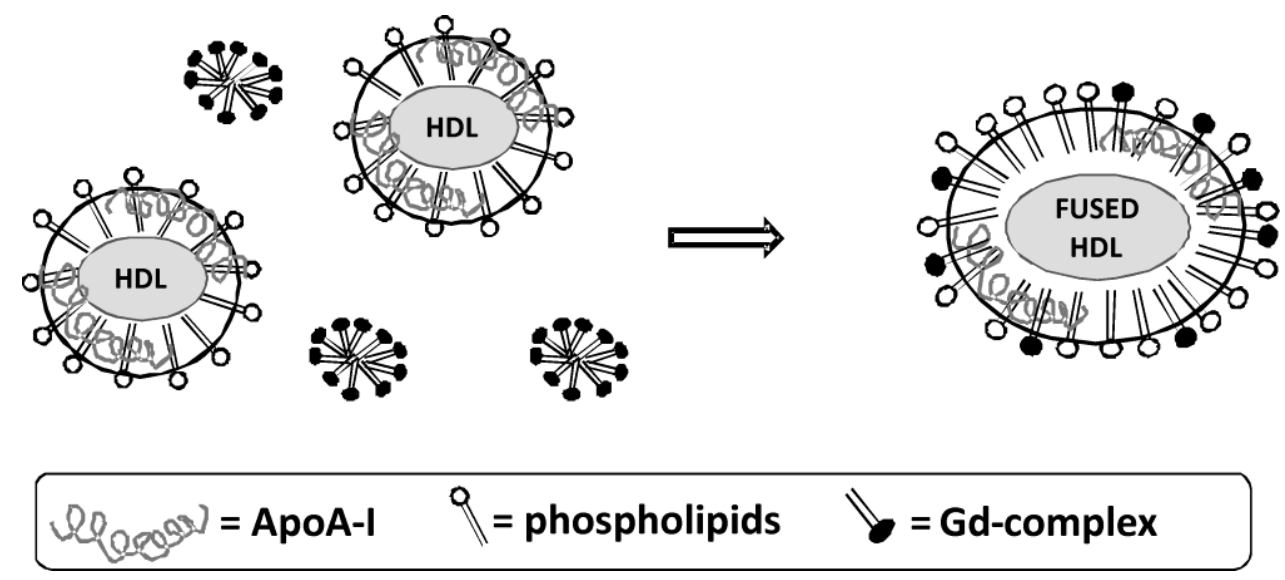

Figure 2 


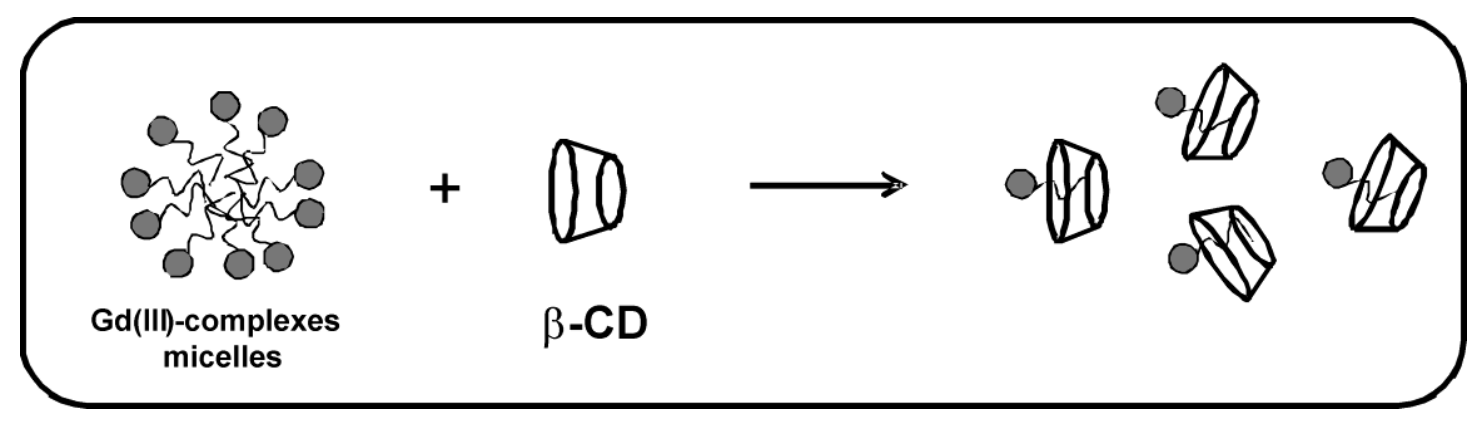

Figure 3

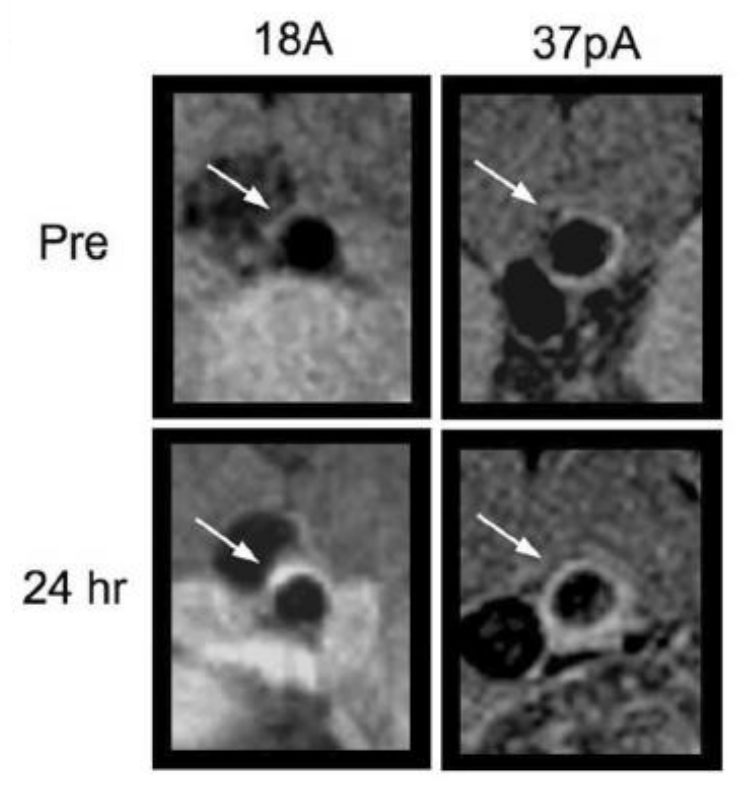

Figure 4 


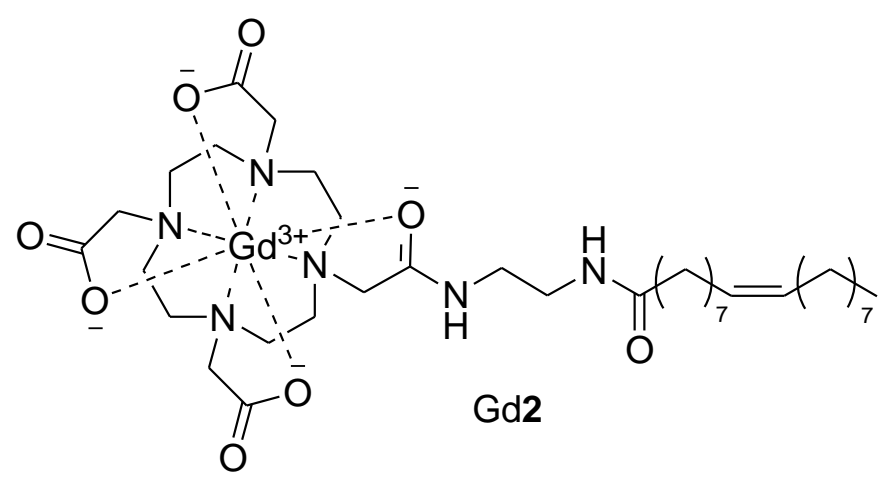

Figure 5

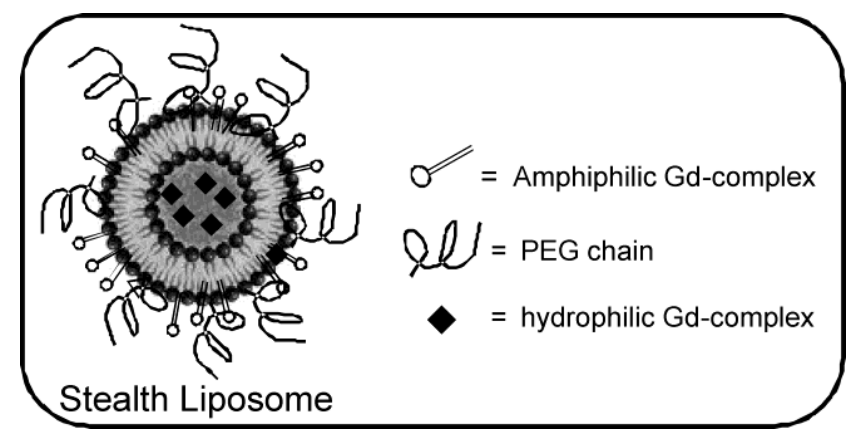

Figure 6 